\section{Regards sur l'économie allemande}

Bulletin économique du CIRAC

98-99 | 2010

Varia

\title{
Population : une société largement métissée
}

\section{Isabelle Bourgeois}

\section{OpenEdition \\ Journals}

Édition électronique

URL : http://journals.openedition.org/rea/4197

DOI : 10.4000/rea.4197

ISBN : 978-2-8218-0892-8

ISSN : 1965-0787

Éditeur

CIRAC

Édition imprimée

Date de publication : 26 octobre 2010

Pagination : 80-81

ISSN : 1156-8992

Référence électronique

Isabelle Bourgeois, «Population : une société largement métissée », Regards sur l'économie allemande [En ligne], 98-99 | octobre 2010, mis en ligne le 05 novembre 2010, consulté le 15 septembre 2020. URL : http://journals.openedition.org/rea/4197

Ce document a été généré automatiquement le 15 septembre 2020

(C) CIRAC 


\title{
Population : une société largement métissée
}

\author{
Isabelle Bourgeois
}

\section{9,6 \% de la population d'origine étrangère}

1 La société allemande est nettement plus métissée qu'on ne croyait, révèle Destatis (communiqué du 14-07-2020). Alors que l'édition 2005 du 'micro-recensement' Mikrozensus, la dernière en date, avait montré que 15,3 millions de personnes vivant en Allemagne sont d'origine étrangère ou issus de l'immigration (voir REA 77/06), l'édition 2010 porte ce nombre à plus de 16 millions, soit $19,6 \%$ de la population en 2009. Cette hausse s'explique d'un côté par un recul de 1,3 million de la population de souche allemande (mortalité), de l'autre par une hausse de 715000 de la population étrangère ou issue de l'immigration (naissances et regroupement familial).

\section{8,5 millions d'Allemands issus de l'immigration}

2 L'Allemagne compte ainsi 7,2 millions d'étrangers (8,8 \% de la population); leur nombre a baissé de 96000 en cinq ans. A l'inverse, celui des Allemands issus de l'immigration a fortement augmenté (+811 000 personnes) ; ils sont aujourd'hui 8,5 millions (10,4\% de la population). Dans cette dernière catégorie, 3 millions de personnes sont originaires de Turquie, 2,9 millions des Etats nés de l'éclatement de l'ex-Union soviétique, 1,5 million de Pologne et autant des Etats issus de l'ex-Yougoslavie. Les Allemands dont les ascendants étaient les « travailleurs invités » (Gastarbeiter) des années 1960 sont peu nombreux en comparaison : 830000 sont d'origine italienne, 403000 d'origine grecque, 172000 d'origine espagnole et 171000 d'origine portugaise.

Destatis a également recensé près d'un million de personnes (978 000 très exactement) dont il est difficile de déceler les origines pour deux raisons essentiellement : soit parce que leurs deux parents sont tous deux d'origine étrangère différente, soit parce qu'il s'agit de personnes rapatriées après le 01-08-1999 (Spätaussiedler) mais qui n'avaient 
alors pas indiqué leur nationalité d'origine (celles qui ont immigré avant cette date sont recensées comme naturalisées).

\section{Ils sont plus jeunes, ...}

4 La structure de la population des Allemands issus de l'immigration présente de grandes différences en comparaison de celle des personnes de souche allemande. Elle se distingue avant tout par sa jeunesse: son âge moyen est de 34,7 ans (contre 45,6). Ensuite, la part des célibataires y est plus élevée ( $45,8 \%$ contre $38,3 \%$ ), et elle est plus masculine $(50,3 \%$ d'hommes contre $48,7 \%)$. Et elle se concentre dans les anciens Länder et à Berlin.

\section{... et moins qualifiés}

5 Autre trait significatif : le manque de qualifications de cette population. 14,0\% des Allemands issus de l'immigration n'ont pas de diplôme du système d'enseignement général ( $1,8 \%$ des Allemands de souche), et $42,8 \%$ d'entre eux n'ont pas de diplôme sanctionnant une formation professionnelle (contre 19,2\%). Dès lors, la part des inactifs parmi les 25-65 ans y est deux fois plus élevée qu'en moyenne allemande $(12,7 \%$ contre $6,2 \%)$; et ils sont plus nombreux à exercer un petit boulot (11,5\% contre $7,0 \%$ de tous les actifs occupés). Enfin, chez ces Allemands de la deuxième ou de la troisième génération, le risque de pauvreté est élevé : $25,2 \%$ des ménages recensés en Allemagne (tous types confondus) est exposé à ce risque si la personne qui rapporte le revenu principal du ménage est issue de l'immigration ; la probabilité tombe à $11,1 \%$ lorsque cette dernière est de souche allemande. Voilà de quoi nourrir les débats sur l'immigration qui font rage actuellement outre-Rhin... (IB)

\section{INDEX}

Mots-clés : population, société multiculturelle, multiculturalisme, immigration, étranger, démographie, jeune, groupe social, qualification 